\title{
MECHANISMS IN ENDOCRINOLOGY \\ Parity and risk of type 2 diabetes: \\ a systematic review and dose-response meta-analysis
}

\author{
Peiyun Li ${ }^{1,2}$, Zhilei Shan ${ }^{1,2}$, Li Zhou ${ }^{1,2}$, Manling Xie ${ }^{3}$, Wei Bao ${ }^{4}$, Yan Zhang ${ }^{1,2}$, \\ Ying Rong ${ }^{1,2}$, Wei Yang ${ }^{1,2}$ and Liegang Liu ${ }^{1,2}$ \\ 1'Department of Nutrition and Food Hygiene, Hubei Key Laboratory of Food Nutrition and Safety, \\ School of Public Health, Tongji Medical College, Huazhong University of Science and Technology, \\ Wuhan, People's Republic of China, ${ }^{2}$ MOE Key Lab of Environment and Health, School of Public Health, \\ Tongji Medical College, Huazhong University of Science and Technology, Wuhan, People's Republic of \\ China, ${ }^{3}$ Department of Pathology and Laboratory Medicine, Emory University School of Medicine, \\ Atlanta, Georgia, USA and ${ }^{4}$ Department of Epidemiology, College of Public Health, University of lowa, \\ lowa City, lowa, USA
}

\author{
Correspondence \\ should be addressed \\ to W Yang or L Liu \\ Email \\ Igliu@mails.tjmu.edu.cn or \\ yw8278@hotmail.com
}

\begin{abstract}
Objective: Epidemiologic studies regarding the association between parity and risk of type 2 diabetes have yielded inconsistent results. Therefore, we performed a systematic review and dose-response meta-analysis to determine the relation between parity and type 2 diabetes risk.

Methods: We searched PubMed and Embase for published epidemiologic studies that assessed the relation between parity and risk of type 2 diabetes up to 31 March 2016. A dose-response random-effects model was used to combine study-specific relative risks (RRs) and $95 \%$ confidence intervals (Cls). Potential sources of heterogeneity were explored by meta-regression and subgroup analyses.

Results: Seven cohort studies, 1 case-control study and 9 cross-sectional studies including 296923 participants were eligible for inclusion. The combined RR for the highest versus lowest category of parity indicated a $54 \%$ increment in type 2 diabetes risk (95\% Cl: 29-83\%). In the cubic spline model, a nonlinear association was found between parity and risk of type 2 diabetes ( $P=0.02$ for nonlinearity). Compared with nulliparous women, the estimated RR $(95 \% \mathrm{Cl})$ of type 2 diabetes for women with one to seven children was 1.01 (0.96-1.07), 1.08 (1.00-1.16), 1.20 (1.12-1.30), 1.32 (1.22-1.42), 1.37 (1.27-1.48), $1.39(1.26-1.52)$ and 1.39 (1.23-1.57) respectively.

Conclusions: Higher parity is significantly associated with an increased risk of type 2 diabetes. Further studies are warranted to fully adjust for the potential confounders and explore the causality between parity and type 2 diabetes risk.

\section{Introduction}

The prevalence of diabetes mellitus has increased substantially in recent decades in both developed and developing countries (1). According to data of the International Diabetes Federation, the number of people living with diabetes is 415 million in 2015 (a number previously forecast for 2030), and will

escalate to 642 million by 2040 (2). Diabetes is also a major risk factor for cardiovascular disease which is still the leading cause of death and imposes a significant public health as well as financial burden on society (3). Thus, the primary prevention of diabetes is clearly imperative.
\end{abstract}

() 2016 European Society of Endocrinology Printed in Great Britain 
Pregnancy is an essential stage of life for most women. In this stage, women are prone to alter their composition of diet, increase energy intake, reduce the duration and intensity of physical activity; these changes of lifestyle may impact on women's health including insulin resistance, fat accumulation, redistribution, dyslipidemia and inflammation, especially on the risk of diabetes and other cardiometabolic disease in future life $(4,5,6,7,8,9)$. Among the different reproductive factors that have been investigated, parity (the number of live births in a woman's lifetime) is less prone to recall bias and misclassification (10). Until now, many studies have focused on the role of parity in the development of type 2 diabetes, suggesting that parity might be independently associated with glucose tolerance $(11,12)$, impaired fasting glucose $(11,13)$ and type 2 diabetes $(13,14,15,16)$. But it remains controversial since other studies have found no relationship between parity and risk of type 2 diabetes $(17,18,19)$. Therefore, we conducted a systematic review and dose-response meta-analysis of current available epidemiologic studies to quantify the association between parity and risk of type 2 diabetes.

\section{Methods}

\section{Search strategy}

We conducted a systematic literature search on the PubMed (Medline) and Embase databases from inception to March 2016 for studies investigating the association between parity and diabetes mellitus. PubMed search terms were (parity OR reproductive history OR live birth OR gravidity) AND ("Diabetes Mellitus" [Mesh] OR "diabetes" [All Fields]). Similar search terms were used for Embase. In addition, we also scrutinized reference from relevant original papers to identify further pertinent studies. No language restrictions were imposed. We followed the standard guidelines for conducting meta-analysis of observational studies and reporting the results (20).

\section{Study selection}

Published studies were included in this meta-analysis if they met the following criteria: the exposure of interest was parity; the outcome was type 2 diabetes; and the study reported adjusted relative risks (RRs), odds ratios (ORs) or hazard ratios (HRs) with 95\% confidence intervals (CIs) for at least three quantitative categories of parity number or provided risk estimates per live birth in original. We excluded nonhuman studies, reviews, commentaries, editorials, letters, meeting abstracts, case reports and studies that did not include parity as the exposure and type 2 diabetes as the outcome. We also excluded studies in which the association of parity with impaired glucose tolerance/impaired fasting glucose, but not the association of parity with type 2 diabetes, was examined. If a study provided raw data which may contribute to the calculation of unadjusted risk estimates, but was not able to derive the adjusted risk estimates, we excluded it due to the lack of controlling for potential effects from confounding factors such as age or body mass index (BMI) on the risk estimates. Two investigators ( $\mathrm{P}$ L and $\mathrm{M} \mathrm{X}$ ) independently screened all studies by title or abstract and then by full-text assessment. Any disagreements were solved by discussion with the senior reviewer (Z S).

\section{Data extraction and quality assessment}

For each eligible study, the following data were extracted: authors, year of publication, study design, study name, country of origin, study period and years of follow-up (for cohort study), participants' age, number of participants and cases, exposure and outcome assessment, covariates adjusted in the multivariable models, parity number categories, the corresponding risk estimates (with their 95\% CIs) and number of cases along with participants or person-years for all categories of parity number. If multiple estimates of the association were available, we abstracted the estimate that adjusted for most potentially confounding variables. If the appropriate data were not readily available, we requested the data from the study's original authors.

For cohort and case-control studies, quality assessments were performed according to the NewcastleOttawa Quality Assessment Scale (21). This scale awards a maximum of 9 points to each cohort study: 4 for selection of participants and measurement of exposure, 2 for comparability of cohorts on the basis of the design or analysis and 3 for assessment of outcomes and adequacy of follow-up. Similar items were performed for casecontrol studies. We assigned scores of $0-3,4-6$ and 7-9 for low, moderate and high quality of studies respectively.

Assessment involving 11 items recommended by the Agency for Healthcare Research and Quality was used for cross-sectional studies (22). The quality of the studies was evaluated according to the established questions which awards a maximum of 11 points. For each item, 1 point was awarded if the answer was 'yes' while 0 point if the answer was 'no', 'unable to determine' or 'not applicable'. 
Data extraction and quality assessment were conducted independently by two investigators (P L and $\mathrm{L} \mathrm{Z}$ ); any discrepancy between the two authors was solved by discussion with the senior reviewer (Z S).

\section{Statistical analysis}

In this meta-analysis, we used the RRs and 95\% CIs as the effect size for all included studies. Since the incidence of diabetes is adequately low in human, the ORs and HRs were considered equivalent to RRs, thereby we used RRs representing all of these measures for simplicity. For studies that did not use the category of lowest parity number as referent, we used the valid count method proposed by Hamling et al. (23) to recalculate the relative risks. Moreover, as for study that reported results separately according to different age groups, races or geographic regions, we treated it as independent reports.

First, we evaluated the summary RR and 95\% CIs for the highest versus the lowest categories of parity number. Given that significant heterogeneity was evident in this analysis, the risk estimates were pooled using the randomeffects model (DerSimonian and Laird method) (24).

Then, we explored the possible linear or nonlinear relationship between parity number and risk of type 2 diabetes using a random-effects dose-response meta-analysis according to the method proposed by Greenland and Longnecker (25) and Orsini et al. (26). Nearly half of the reports have investigated the linear relation between parity and type 2 diabetes, and provided RR per live birth in original. Thus, we explored the possible linear relationship at first. For reports that did not explore the linear relationship, we computed an RR with 95\% CIs for an increased number of parity according to the existing data. The distribution of cases and person-years/number of participants and the RRs with 95\% CIs for at least three quantitative exposure categories were extracted according to the method. For each study, the median or mean level of exposure category was assigned to the corresponding RR. If the median or mean exposure level was not reported in the study, we assigned the midpoint of upper and lower boundaries in each category as the value of exposure. When the highest category was open-ended, we assumed that the lower boundary plus 25\% increment was the median level. To further examine the shape of the association, we evaluated a potential curve linear association between parity number and risk of diabetes, using restricted cubic splines with four knots at percentiles 5, 35, 65 and 95\% of the distribution (27).
According to the method, the spline function is constrained to be linear in the tails, and $P$ value for curve linearity or nonlinearity was calculated by testing the null hypothesis that the regression coefficient of the second and third spline was equal to zero (28).

The heterogeneity among studies was estimated by using the Cochran's Q test and $I^{2}$ statistic (29). Heterogeneity was considered statistically significant at $P<0.10$. Low, moderate and high degree corresponded to $I^{2}$ statistic of 25,50 and $75 \%$ respectively (29). We conducted a meta-regression analysis and subgroup analyses to explore sources of heterogeneity. Subgroup analyses were performed according to the study design, geographic location, year of publication, number of cases and participants, and methods of outcome ascertainment. We also stratified the meta-analysis by whether adjustment for potential confounders, such as age, BMI, family history of diabetes mellitus, education and income, was performed. To test the robustness of the associations, we performed sensitivity analyses by omitting one study at a time and estimating a pooled RR for the rest of the studies to evaluate whether the results were markedly influenced by a single one. The Begg and Egger tests were applied to assess the possible publication bias (30). All the data analyses were performed with Stata version 12.0 (Statacorp). Two-sided $P<0.05$ was considered statistically significant.

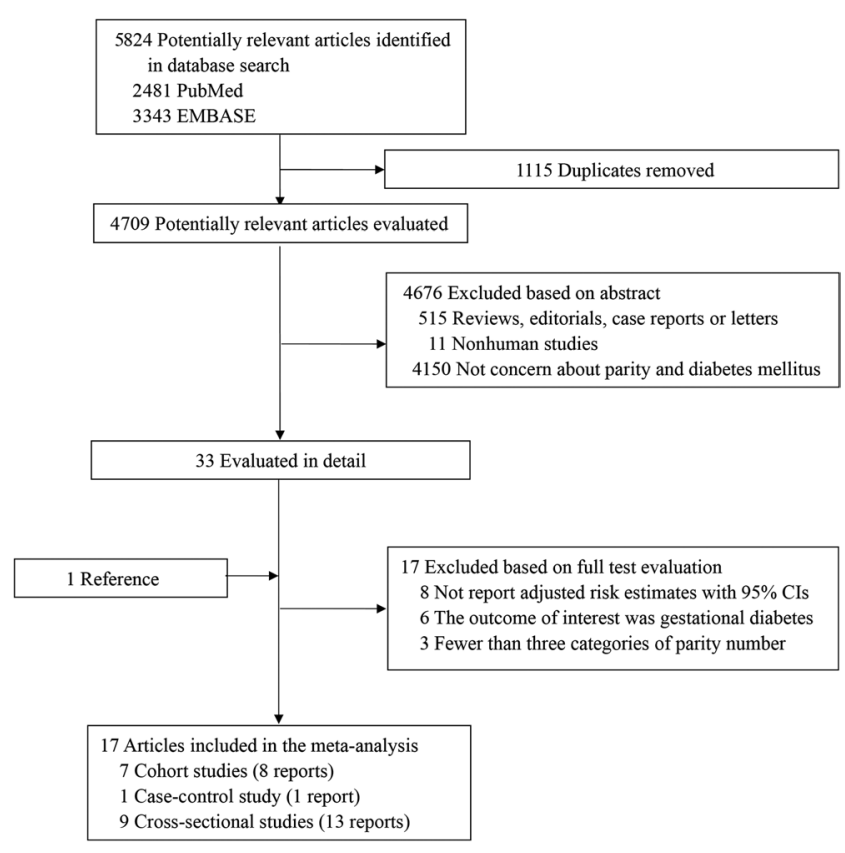

Figure 1

Flow diagram of literature search and study selection. 
|

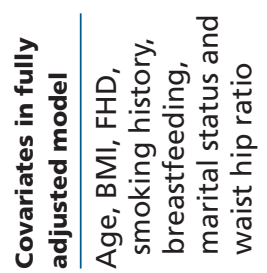

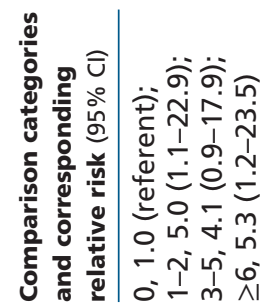

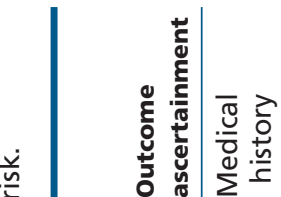

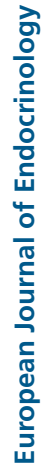

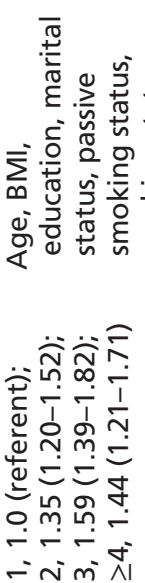

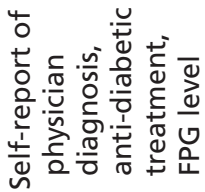

竝

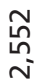

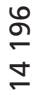

$\stackrel{\text { ค }}{\wedge}$

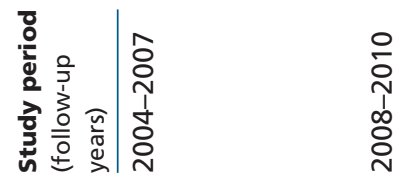

:

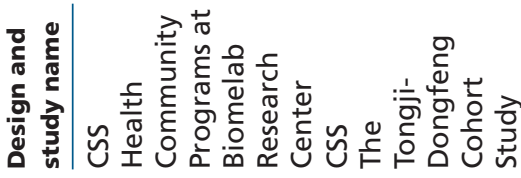

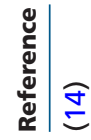

$\widehat{\underline{\underline{m}}}$

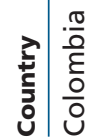

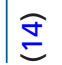

a

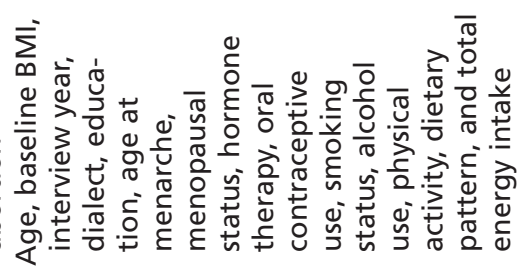

후으ำ

实市

๘)

包的罂

isti

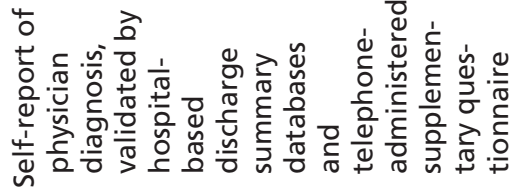

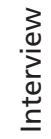

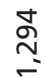

$\overline{0}$
$\stackrel{\sim}{\sim}$

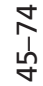

ठั่

ตั๊

0
$\frac{0}{0}$
$\frac{0}{0}$
$\frac{0}{5}$

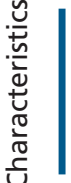

$\frac{5}{\frac{0}{0}}$

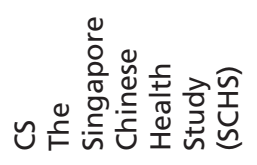

$\stackrel{\overbrace n}{=}$ 
$\infty$

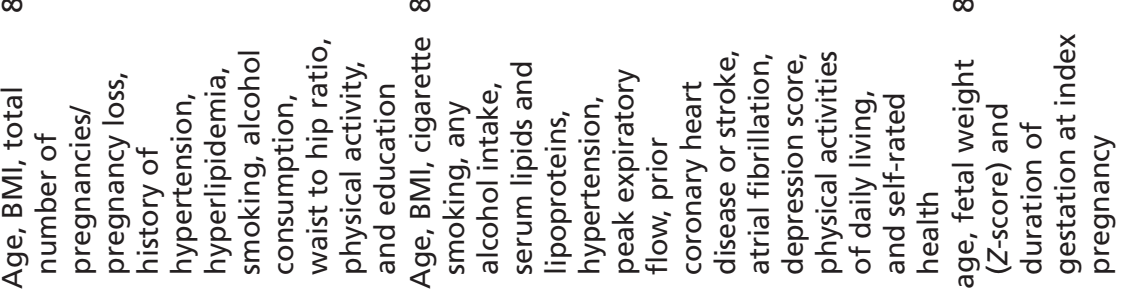

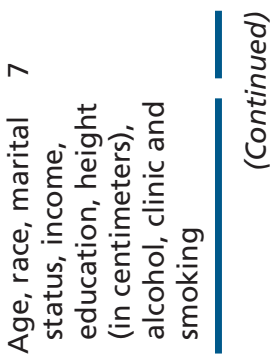

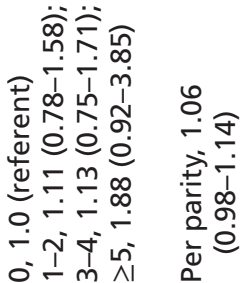

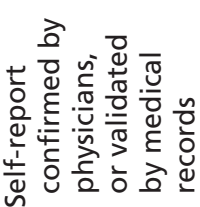

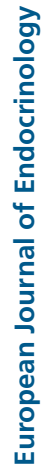

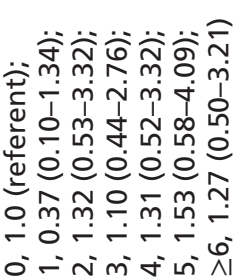

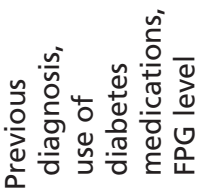

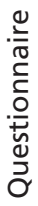

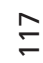

$\stackrel{5}{\underline{n}}$

옷

운

รั응

颃

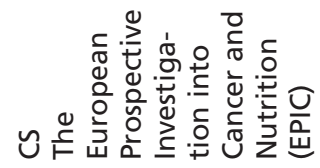

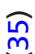

$\stackrel{\circ}{\infty}$
$\stackrel{\circ}{1}$
$\infty$
$\stackrel{\circ}{\sigma}$

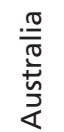

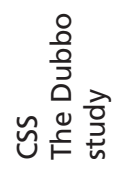

ふ্ণ

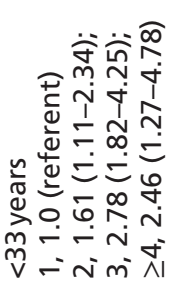

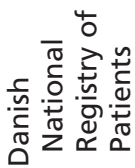

告

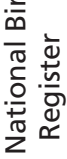

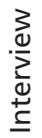

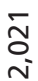

$\circ$
8
8

$\stackrel{\overline{6}}{\sim}$

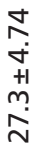

เั่

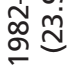

$\stackrel{\llcorner}{\sim}$

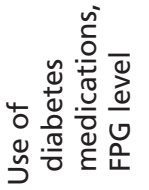

飐

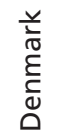

ธิ

$\tilde{y}$

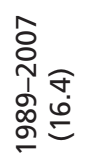

$\stackrel{0}{=}$

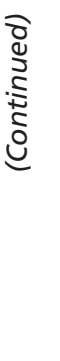



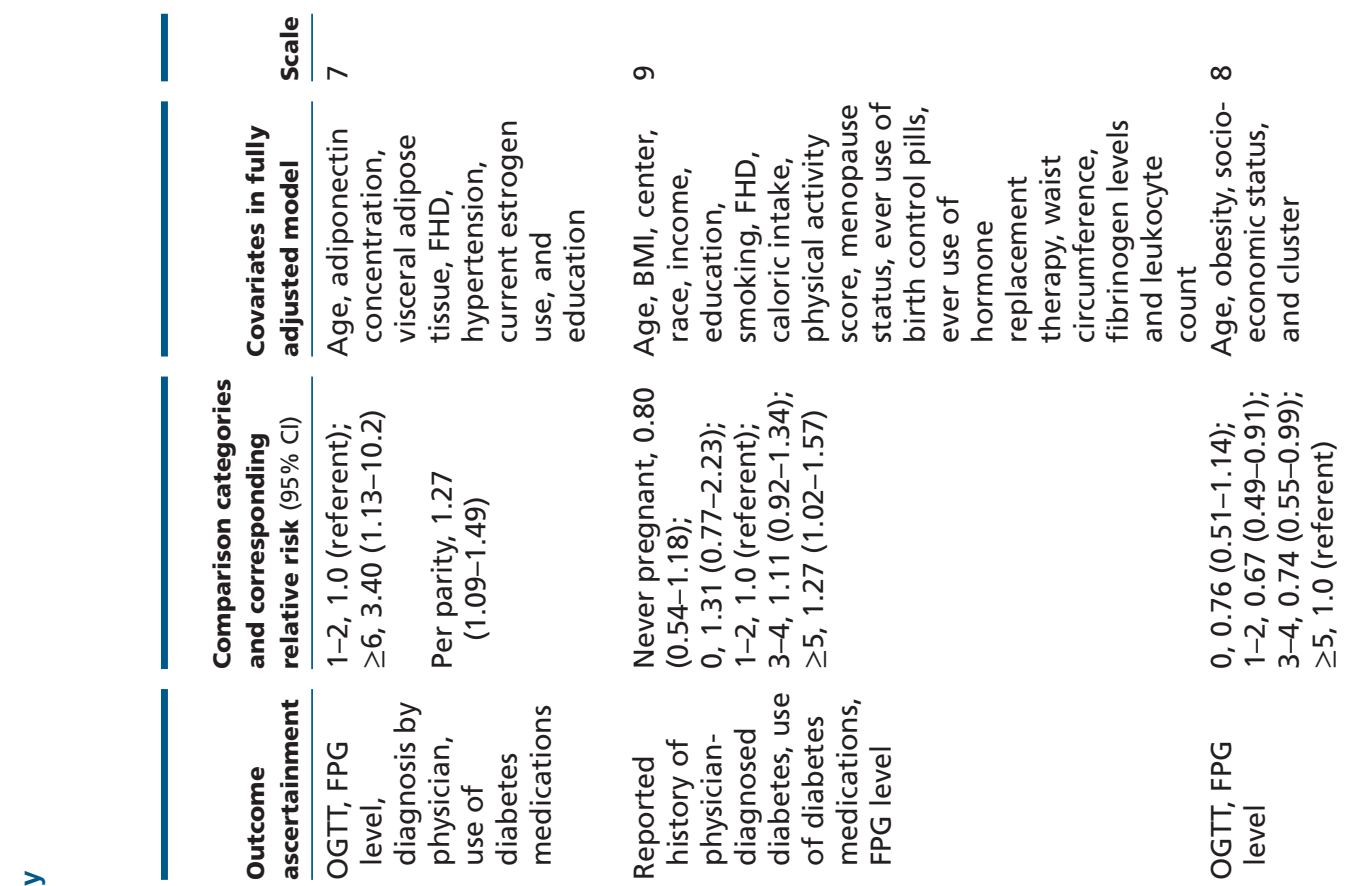

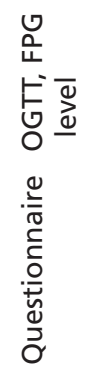
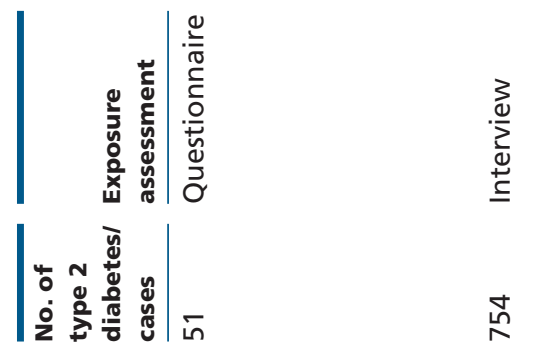

茫

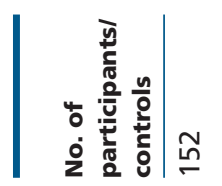

离

$\stackrel{\infty}{\infty}$<smiles>C=CC</smiles>

ț
ஸे

$\stackrel{\llcorner}{N}$

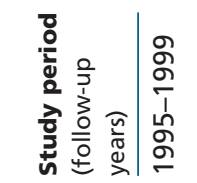

$\stackrel{\infty}{\circ}$
$\stackrel{\circ}{1}$
$\stackrel{\circ}{\circ}$
$\stackrel{\circ}{\circ}$

m
ஸे
ळे
$\stackrel{2}{\circ}$

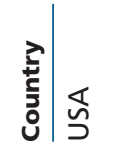

$\overleftarrow{s}$

$\frac{.00}{\frac{\pi}{\pi}}$

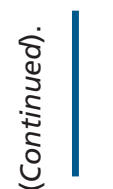

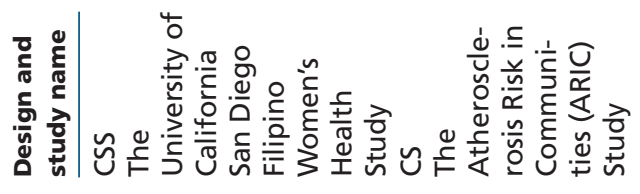

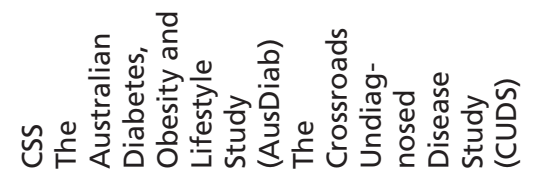

ळ্

$\stackrel{\widehat{\infty}}{=}$ 
$\infty$

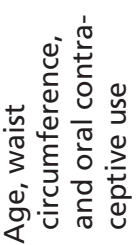

6 $\infty$

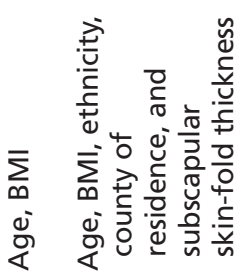

N

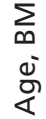

$\infty$

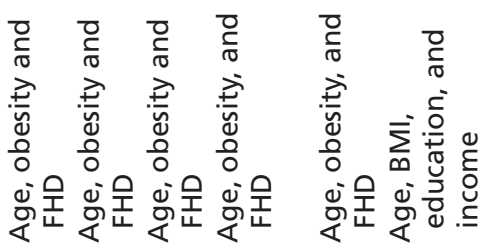

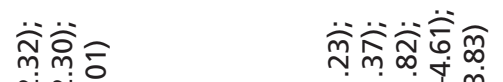

순ำ

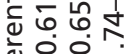

4ै

은 ำ ำ

어요

ำ

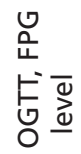

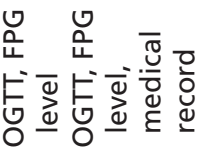

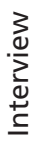

ホ

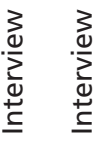

$\stackrel{\circ}{\circ}$

$\stackrel{m}{m}$

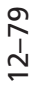

号

$\frac{\pi}{0}$
$\frac{\pi}{\pi}$
$\frac{\pi}{5}$

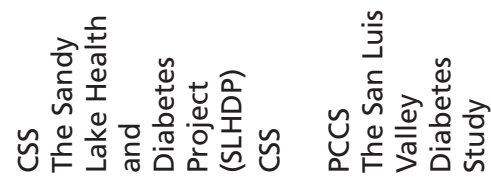

守
瓦

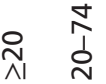

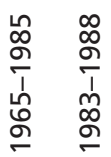

军

离

密

$\widehat{\widehat{g}}$

占

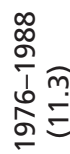

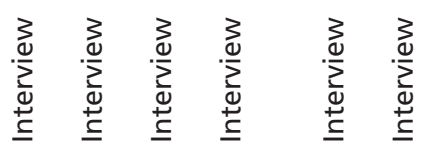

ร $\stackrel{0}{\sim} \stackrel{\infty}{\circ}$ in $\stackrel{\circ}{\circ}$

$\stackrel{\stackrel{\bullet}{\circ}}{\stackrel{m}{=}}$

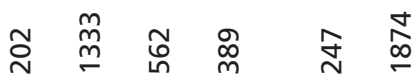

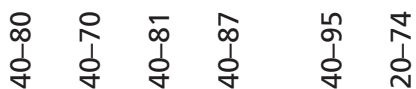

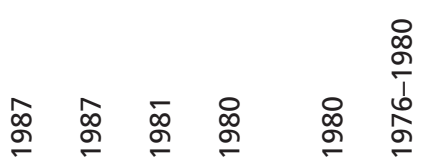

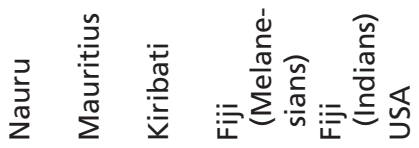

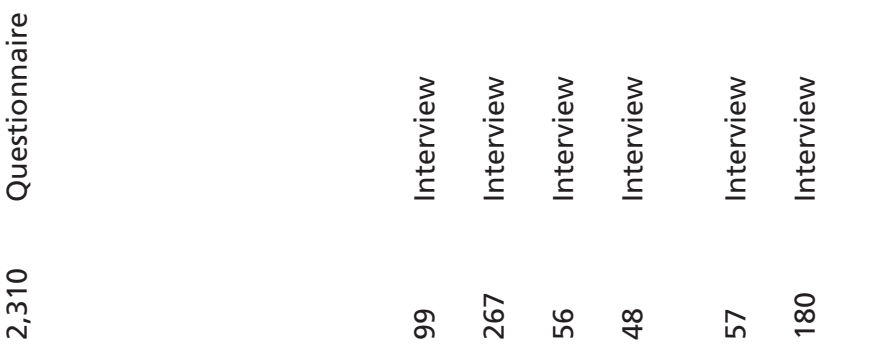

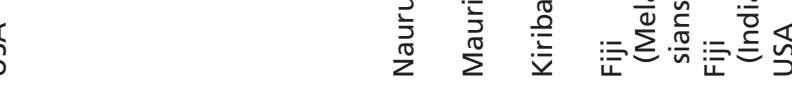

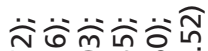

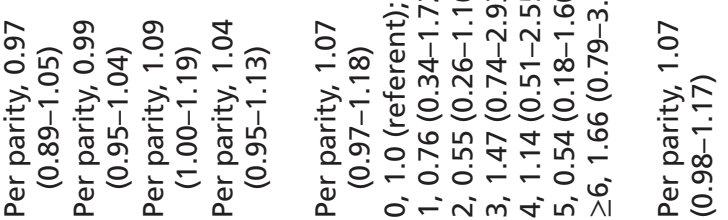

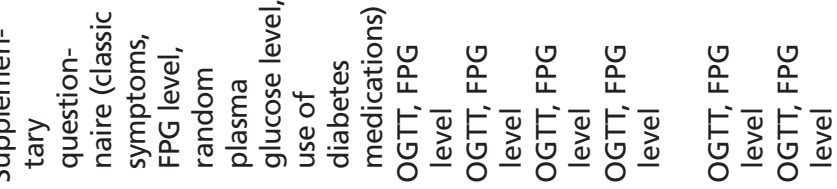

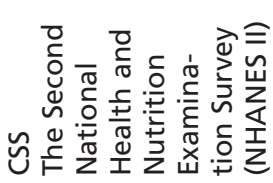




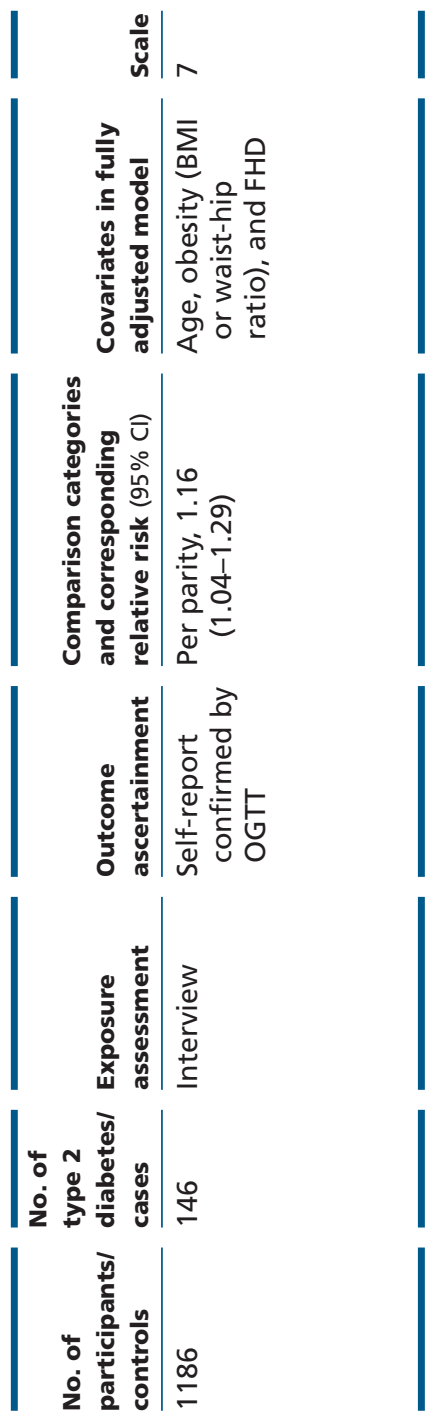

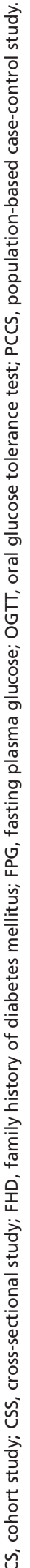

\section{Results}

\section{Literature search}

Figure 1 shows the flow diagram of the procedure used to identify the relevant studies. We identified 2481 articles from PubMed and 3343 articles from Embase before 31 March 2016. After exclusion of duplicates and studies that did not meet the predefined selection criteria, 33 potentially relevant articles were initially selected for this meta-analysis. After evaluating the full texts, 17 articles were excluded. Eight articles were further excluded owing to insufficient data; although $3(31,32,33)$ of them provided original data, we could not calculate adjusted RRs with 95\% CIs accordingly. Six articles were excluded because the outcome of interest was gestational diabetes mellitus. Other three articles in which fewer than three categories of parity number were provided were excluded for no contribution to the estimation of dose-response analysis. Moreover, one publication (34) was included by scanning reference from relevant papers. In one paper, the researchers indicated that they conducted a crosssectional study initially, and followed up the remainders after excluding patients of diabetes for years (17), so we just included the results of the prospective study to avoid bringing the same subjects. Finally, 17 articles $(12,13,14$, $15,16,17,18,19,34,35,36,37,38,39,40,41,42$ ) were eligible for this meta-analysis including 7 cohort studies $(12,15,16,17,19,35,36), 1$ case-control study (38) and 9 cross-sectional studies $(13,14,18,34,37,39,40,41$, 42). For studies conducted by Naver et al. (16) and Collins et al. (42), the estimates were reported by different age groups or geographic regions; we treated them as seven separate reports. Therefore, our meta-analysis included 17 articles with 22 independent reports.

\section{Study characteristics}

Characteristics of the 17 eligible studies are shown in Table 1. Our included studies, which comprised 296923 participants, were published between 1989 and 2015. Eight studies were conducted in the North America $(12,17,19,34,36,38,40,41)$, one in South America (14), two in Europe $(16,35)$, three in Asia $(13,15,37)$, two in Oceania $(18,39)$ and one study in both Oceania and Africa (42). The average of follow-up duration of cohort studies was 11.4 years. The sample size of the included cohort studies ranged from 1186 to 113606 and the number of type 2 diabetes cases varied from 146 to 2310. For cross-sectional studies, the number of 
participants ranged from 152 to 14196 (51-2552 people were considered as type 2 diabetes). Study-specific quality scores were summarized in Supplementary Tables 1 and 2, see section on supplementary data given at the end of this article. The quality score ranged from 7 to 9 with a median score of 8 for all cohort and case-control studies. Meanwhile, all the cross-sectional studies scored 6-9 points, which suggested high quality of the studies included in the meta-analysis.

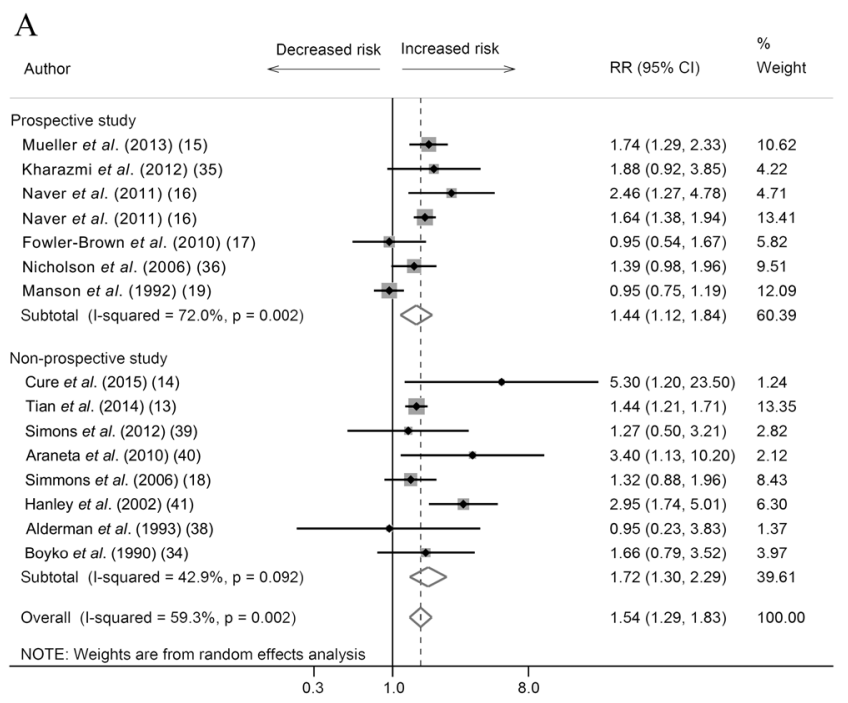

B

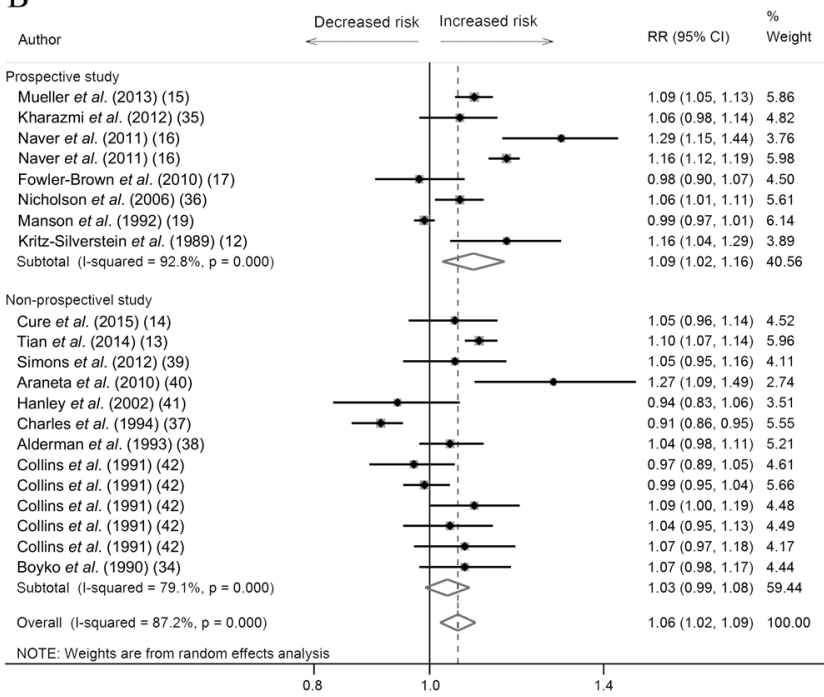

Figure 2

Forest plots of the associations between parity and risk of type 2 diabetes. (A) Forest plot of parity number (highest versus lowest) and type 2 diabetes risk; (B) Forest plot of linear dose-response relation between parity (per live birth) and type 2 diabetes.

\section{Highest vs lowest number of parity}

Fifteen reports from 14 studies $(13,14,15,16,17,18$, $19,34,35,36,38,39,40,41)$ described the association between parity number and type 2 diabetes risk. Eleven reports considered nulliparous as the lowest category of parity while 3 reports $(13,16)$ treated one live birth as the lowest. One report (40) considered one or two live births as the lowest category of parity number. The pooled RR of type 2 diabetes risk for the highest vs lowest categories of parity was 1.54 (95\% CI: 1.29-1.83). There was moderate heterogeneity among the studies $\left(I^{2}=59.3 \%, P=0.002\right)$ (Fig. 2A).

In a sensitivity analysis, exclusion of one study at a time from the pooled estimate had little impact on the overall effect size. To confirm the robustness of the results, we conducted additional sensitivity analyses. We excluded four reports $(13,16,40)$ that did not refer to nulliparous as the lowest category of parity number. The pooled RR was 1.47 (95\% CI: 1.15-1.89), with no substantial change. In addition, we performed a sensitivity analysis by including the three articles $(31,32,33)$ that were excluded previously and another five reports (42) that also provided raw data for the calculation of unadjusted RRs; the pooled RR was 1.78 (95\% CI: 1.42-2.23).

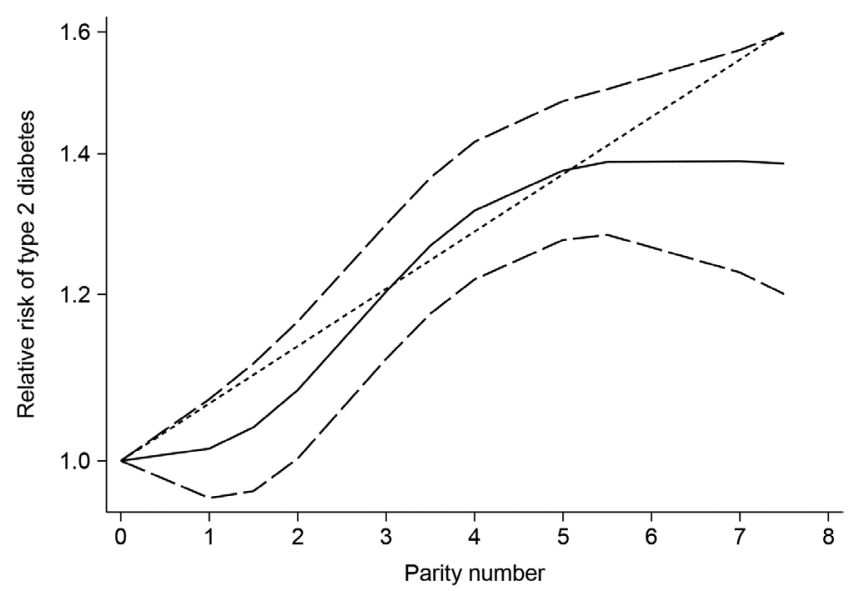

Figure 3

Dose-response analyses relating parity to type 2 diabetes risk. There was a nonlinear association between parity and risk of type 2 diabetes ( $P=0.02$ for nonlinearity). Parity number was modeled with restricted cubic splines by a random-effects dose-response model. Nulliparous was used as the reference to estimate all relative risks. Dotted lines represent the $95 \% \mathrm{Cls}$ for the fitted trend. 


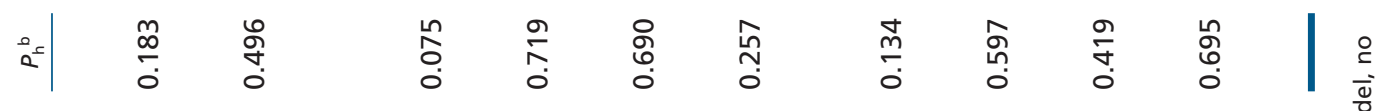

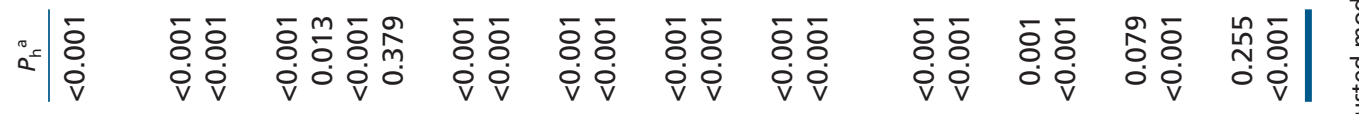
产|

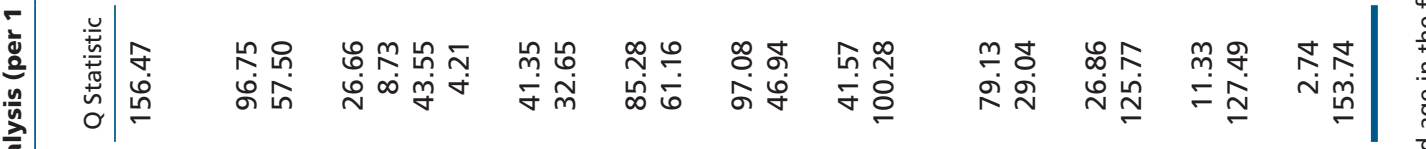

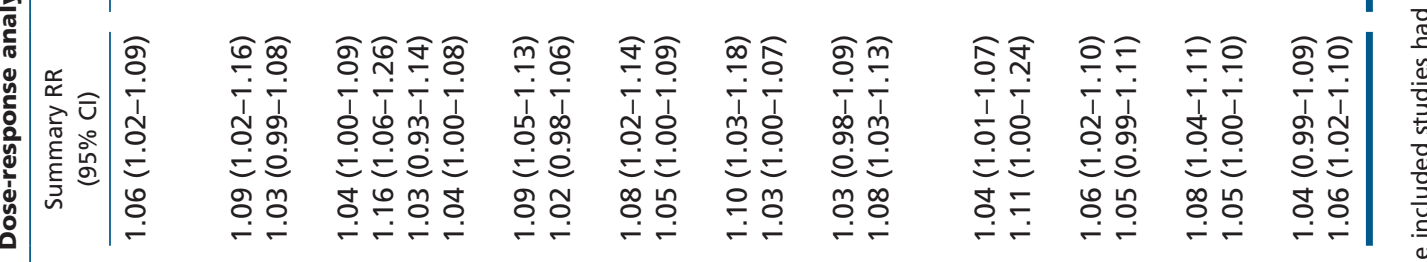

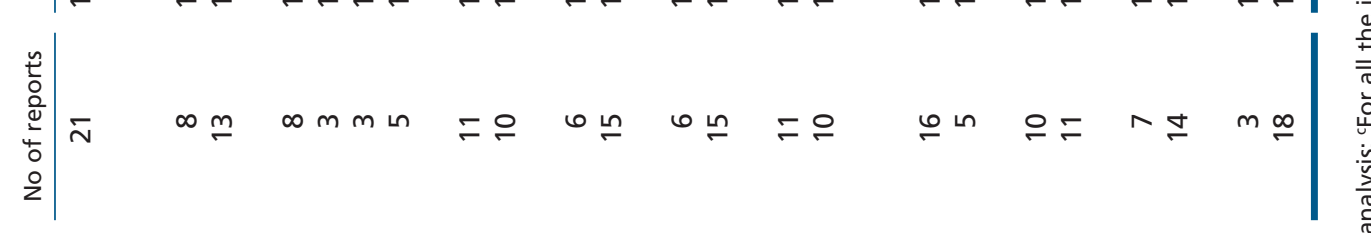

$\stackrel{\substack{n \\ \hdashline}}{i}$

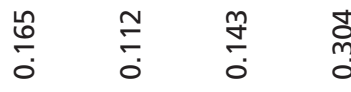

\begin{tabular}{llll}
$\stackrel{n}{N}$ & $\stackrel{n}{n}$ & $\infty$ & $\infty$ \\
\hdashline & 0 & $\infty$ & $\stackrel{\infty}{N}$ \\
0 & 0 & 0 & 0
\end{tabular}

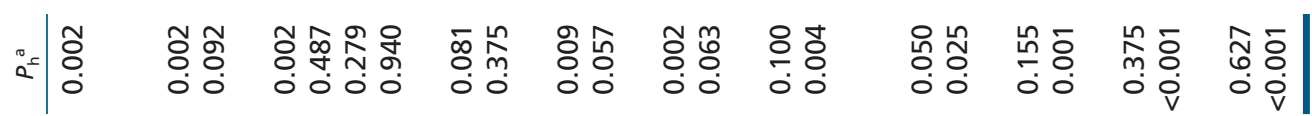

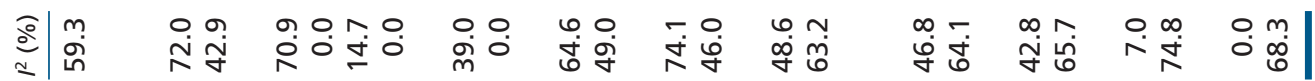

$\underset{\check{\tau}}{-} \stackrel{2}{\sim}$

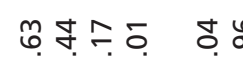

nim $n \infty$

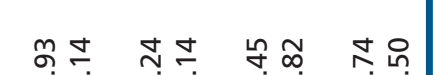

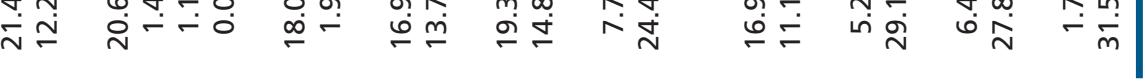

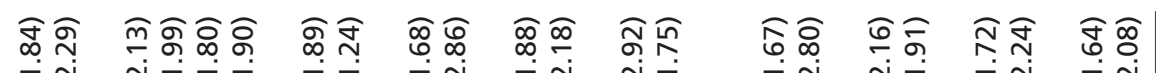

\丶

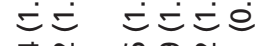

落

$=0$

EE E्E

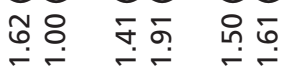

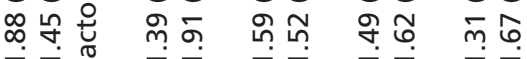

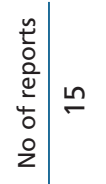

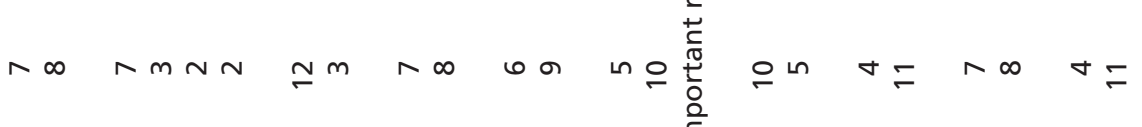

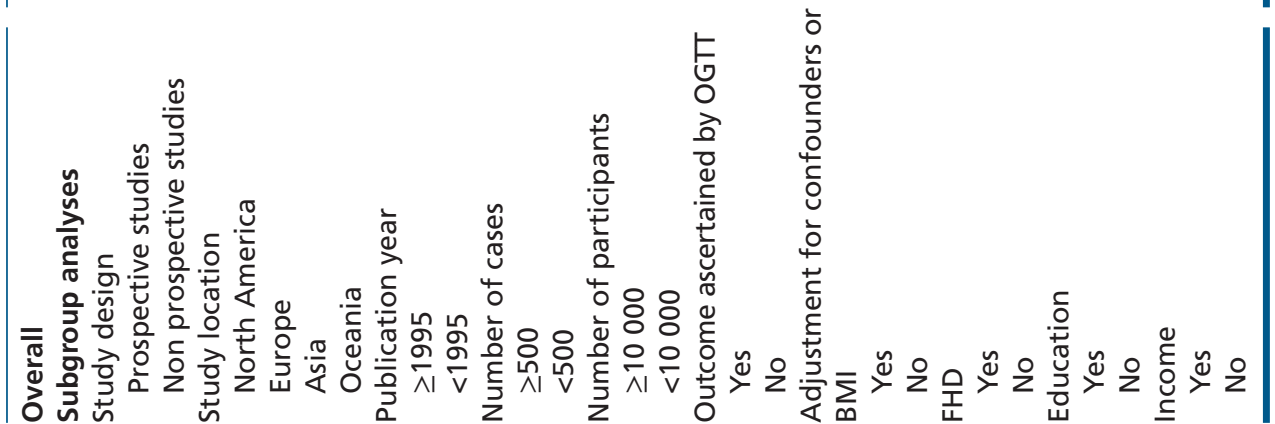

$\stackrel{\frac{1}{2}}{\frac{\pi}{2}}$

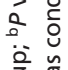




\section{Dose-response meta-analysis}

When assuming a linear relationship, there were 16 studies $(12,13,14,15,16,17,19,34,35,36,37,38,39$, $40,41,42$ ) with 21 reports available for the dose-response analysis. The combined RR for type 2 diabetes was 1.06 (95\% CI: 1.02-1.09) per live birth, with evidence of high heterogeneity $\left(I^{2}=87.2 \%, P<0.001\right)$ (Fig. 2B). Eight studies $(13,14,15,16,17,19,36,39)$ with nine reports were included in the cubic spline model, and a nonlinear association between parity and risk of type 2 diabetes was found (Fig. 3, $P=0.02$ for nonlinearity). Compared with nulliparous women, the estimated RR of type 2 diabetes was 1.01 (95\% CI: 0.96-1.07) for women with one child, 1.08 (95\% CI: 1.00-1.16) for women with two children, 1.20 (95\% CI: 1.12-1.30) for women with three children, 1.32 (95\% CI: 1.22-1.42) for women with four children, 1.37 (95\% CI: 1.27-1.48) for women with five children, 1.39 (95\% CI: 1.26-1.52) for women with six children and 1.39 (95\% CI: 1.23-1.57) for women with seven children.

In a sensitivity analysis, exclusion of one study at a time from the pooled estimate had little impact on the overall effect size. We also examined studies that presented RR of type 2 diabetes per live birth in original papers in linear dose-response analysis $(12,34,35,37,38$, 40, 41, 42); the pooled RR was attenuated to 1.04 (95\% CI: 0.99-1.08). Additionally, the summary RR of type 2 diabetes was 1.06 (95\% CI: 1.03-1.10) per live birth after including studies $(31,32,33,42)$ for which crude estimates could be derived, and the shape of the nonlinear association between parity and type 2 diabetes was similar to the previous one. Overall, the sensitivity analyses did not lead to any significant changes on the association between parity and type 2 diabetes risk.

\section{Subgroup analyses}

Subgroup analyses were carried out to examine the sources of heterogeneity. The associations of parity number with risk of type 2 diabetes were similar in subgroup analyses (Table 2).

In the analysis of highest versus lowest categories of parity and type 2 diabetes risk, no significant heterogeneity between subgroups was found. The between-study heterogeneity was largely reduced when the analysis was stratified according to study location and publication year. Comparing with the high heterogeneity, we observed among studies that did not adjust for education and income, the summary results of the studies that adjusted for aforementioned confounders had evident lower heterogeneity. This result may be attributable to the hypothesis that lower socioeconomic status might lead to both higher parity and risk of diabetes. Almost all strata showed positive associations, although not all of them showed statistical significance. Similar patterns were also observed in the dose-response analyses.

It is worth mentioning that the association between parity number and risk of type 2 diabetes was familiar when stratified by study design. When considered prospective studies, the pooled RR of type 2 diabetes risk was 1.44 (95\% CI: 1.12-1.84) for the highest vs lowest categories of parity and was 1.09 (95\% CI: 1.02-1.16) per live birth (Fig. 2). Furthermore, when we removed nonprospective studies $(13,14,39)$ out of the cubic spline model, there was still a J-shaped association between parity and risk of type 2 diabetes, and women with at least four children had significantly higher risk of type 2 diabetes. More specifically, compared with nulliparous women, the estimated RR of type 2 diabetes was 1.12 (95\% CI: 1.02-1.23) for women with four children, 1.18 (95\% CI: 1.07-1.30) for women with five children, 1.22 (95\% CI: 1.08-1.34) for women with six children and 1.26 (95\% CI: $1.08-1.40)$ for women with seven children.

\section{Assessment of publication bias}

There was no evidence of substantial publication bias for all meta-analyses according to the Begg and Egger tests ( $P>0.05$ for both tests).

\section{Discussion}

To the best of our knowledge, this is the first metaanalysis exploring the association between parity and type 2 diabetes risk. Our results indicated that parity was positively associated with type 2 diabetes. Specifically, a nonlinear association between parity and type 2 diabetes risk was observed in the cubic spline model. Higher parity (at least 3 live births) was found to be associated with significantly increased risk of type 2 diabetes.

Our results were consistent with the previous epidemiologic studies $(13,14,15,16,35,36,40)$. Charles et al. (37) found that parity was associated with a significantly reduced risk of diabetes after adjustment for age and BMI. However, the individuals in that study were known to suffer from high rates of diabetes and the age ranged widely, which might lead to the particularity of the results. 
In order to examine the shape of the possible association between parity and type 2 diabetes, a doseresponse analysis was deemed essential. In our linear dose-response analysis, the risk of type 2 diabetes was increased by $6 \%$ for each birth. In the cubic spline model, a nonlinear association was observed: higher parity (at least 3 live births) was associated with a significantly elevated risk of type 2 diabetes. It is noteworthy that the reports we included in the analysis of linear or nonlinear relation were different, because only a few studies $(13,14,15,16,17,19,36,39)$ had sufficient data for nonlinear dose-response analysis apart from providing the RR of linear relation between parity and risk of type 2 diabetes. Thus, linear and nonlinear relations were both tested to quantify the association in this study. Aside from type 2 diabetes, prospective studies in populations have found an increased risk of metabolic syndrome in multiparous women compared with nulliparous (43, 44). Accumulating evidence also suggests that parity is associated with a higher risk of all-cause mortality in later life, especially with cardiovascular and cerebrovascular mortality $(8,45)$.

Several potential mechanisms might contribute to the $\mathrm{J}$-shaped association between parity and type 2 diabetes risk. Generally, more than $80 \%$ of women in high-income countries bear at least one child (46), as do upward of $90 \%$ of women in most lower- and middle-income nations (6). This data suggested that women who did not have any children may suffer from infertility in addition to personal will. Besides, according to previous studies, several causes of infertility were associated with a higher diabetes risk such as polycystic ovary syndrome (47), ovulation disorders and tubal factor (48). This could partly explain the platform stage of the J-shaped relationship between parity and diabetes. The increase in type 2 diabetes risk with increasing parity after two children may be the results of accumulative physiological and lifestyle changes. First, a pronounced state of insulin resistance in peripheral tissues is induced in pregnancy period; gestational hormones might promote insulin resistance and pancreatic $\beta$ cell proliferation (49). The $\beta$ cell mass expands in response to the progressive insulin resistance to maintain maternal euglycemia during pregnancy and postpartum period (50). In susceptible nondiabetic women, insulin resistance may be severe enough to exhaust $\beta$ cells and induce to the occurrence of gestational diabetes mellitus or even a permanent derangement of insulin secretion in later life (51). Mueller et al. (15) found parity was positively associated with HbA1c levels in women reporting no history of diabetes diagnosis; this result suggested that even in nondiabetic women, multiparity may alter long-term glucose homeostasis due to repeated exposure to the hormone alterations. Second, pregnancy has been found to be accompanied by a systemic inflammatory state as demonstrated by modest elevations in pro- and anti-inflammatory cytokines such as IFN- $\gamma$ and TNF- $\alpha$ (7), which play important roles in the occurrence of insulin resistance and type 2 diabetes (52). Third, there is an increase in placental oxidative stress levels during pregnancy, even in a healthy placenta. A high placental mitochondrial activity could trigger an increase in reactive oxygen species production (53) which may serve as an important trigger of insulin resistance and type 2 diabetes (54). Pancreatic $\beta$ cell may be more vulnerable to oxidative stress through pregnancy-induced increment in reactive oxygen species production and other physiologic changes (55). Moreover, pregnancy complications are considered to be associated with a greater risk of diabetes $(56,57$, 58 ), and the recurrence of pregnancy complications in subsequent pregnancies may exert a cumulative burden on diabetes proceeding. Finally, pregnancy also impacts women's dietary habits and physical activity. Lack of exercise and a high-calorie diet during pregnancy may induce excess gestational weight gain and postpartum obesity which could have impact on a woman's health in future (59). Mamun et al. (60) found that mothers who gained excess weight during pregnancy were 1.47 times more likely to experience diabetes compared with the mothers who gained adequate weight.

Therefore, the cumulative effect of these adaptations and risks may contribute to the above-noted J-shaped association between parity and type 2 diabetes risk. Nevertheless, it is still unclear whether normal pregnancies with increasing parity exert a cumulative burden on diabetes proceeding, whether advanced maternal age or other potential factors of multiparous women exert more diabetes risk or whether women at high diabetes risk have more children. Thus, more insight into the association between parity and maternal risk of type 2 diabetes is warranted and more potential confounders should be taken into consideration in the study design.

This meta-analysis has several strengths. First, we included seven cohorts, one case-control and nine crosssectional studies with large sample size which provided sufficient statistical power to detect potential association. The average score is 8 for cohort and case-control studies and 7.9 for cross-sectional studies, which ensured the high quality of the included studies. Second, we investigated a dose-response relation between parity number and risk of type 2 diabetes, allowing us to examine the shape of this 
possible association. Linear and nonlinear relations were both tested to quantify the association. Third, in each of the included studies, we used the risk estimates from the multivariable models adjusting for most established risk factors in order to better control the confounders. In addition, subgroup analyses were also conducted to explore whether some factors could explain the results.

Several limitations of our study should also be acknowledged. First, as a meta-analysis of observational epidemiologic studies, the limitations inherent to combining estimate risk from studies with heterogeneous study designs could not be avoided. Cohort studies are less susceptible to recall bias than case-control and crosssectional studies due to the prospective design. Considering that parity is less prone to recall bias and misclassification than other reproductive factors, and subgroup analyses that included prospective studies only did not show any significant difference, this matter may not substantially influence the results. Second, even though we made an attempt to control confounding factors using the adjusted estimates from multivariate models from contributing studies, we could not perform additional adjustments for residual or unmeasured confounders. The exclusion of papers that did not report adjusted estimates may slightly underestimate the association, but the sensitivity analyses and assessment of publication bias reassured that our results were unlikely to be appreciably affected by such exclusion. Finally, significant heterogeneity was present in the analyses, and sources of heterogeneity were not completely clear, which might be partly due to different study locations or the difference in confounder adjustment in the included studies.

\section{Conclusions}

Findings from this systematic review and dose-response meta-analysis suggested that higher parity was associated with an increased risk of type 2 diabetes. Further studies are warranted to fully adjust for the potential confounders and explore the causality between parity and type 2 diabetes risk.

\section{Supplementary data}

This is linked to the online version of the paper at http://dx.doi.org/10.1530/ EJE-16-0321.

\section{Declaration of interest}

The authors declare that there is no conflict of interest that could be perceived as prejudicing the impartiality of the review.

\section{Funding}

This work was funded by the National Science and Technology Support Program (2012BAI02B02). The funder had no role in study design, data collection and analysis, decision to publish or preparation of the manuscript.

\section{Author contribution statement}

P L formulated the study, searched the databases and checked them according to the inclusion and exclusion criteria, extracted and analyzed the data, and drafted and revised the manuscript. Z S helped formulate the study, provided advice on meta-analysis methodology and contributed to writing, reviewing or revising the manuscript. L $Z$ helped extract quantitative data from the eligible papers and commented on drafts. $\mathrm{M} X$ and $\mathrm{Y} Z$ searched the databases and checked them according to the inclusion and exclusion criteria and commented on drafts. W B and $Y R$ provided advice on meta-analysis methodology and contributed to writing, reviewing or revising the manuscript. W $Y$ helped develop search strategies, supervised the study and revised the manuscript. L L formulated the study, supervised the study and had full access to all the data in the study and takes responsibility for the integrity of the data and accuracy of the data analysis. All authors have read and approved the final version.

\section{Acknowledgments}

The authors thank the investigators, staff and participants of all studies included in our meta-analysis for their contributions.

\section{References}

1 Chen L, Magliano DJ \& Zimmet PZ. The worldwide epidemiology of type 2 diabetes mellitus - present and future perspectives. Nature Reviews Endocrinology 20128 228-236. (doi:10.1038/nrendo.2011.183)

2 International Diabetes Federation. IDF Diabetes Atlas, 7th edn. (available at: http://www.diabetesatlas.org/). Accessed on 31 March 2016.

3 Roger VL, Go AS, Lloyd-Jones DM, Benjamin EJ, Berry JD, Borden WB, Bravata DM, Dai S, Ford ES, Fox CS et al. Heart disease and stroke statistics-2012 update: a report from the American Heart Association. Circulation 2012125 e2-e220. (doi:10.1161/cir.0b013e31823ac046)

4 Ryan EA. Hormones and insulin resistance during pregnancy. Lancet 2003362 1777-1778. (doi:10.1016/s0140-6736(03)14942-2)

5 Kaaja RJ \& Greer IA. Manifestations of chronic disease during pregnancy. JAMA 2005294 2751-2757. (doi:10.1001/ jama.294.21.2751)

6 Gunderson EP. Childbearing and obesity in women: weight before, during, and after pregnancy. Obstetrics and Gynecology Clinics of North America 200936 317-332. (doi:10.1016/j.ogc.2009.04.001)

7 Soeters PB \& Grimble RF. The conditional role of inflammation in pregnancy and cancer. Clinical Nutrition 201332 460-465. (doi:10.1016/j.clnu.2012.07.010)

8 Beral V. Long term effects of childbearing on health. Journal of Epidemiology and Community Health 198539 343-346. (doi:10.1136/ jech.39.4.343)

9 Rich-Edwards JW, Fraser A, Lawlor DA \& Catov JM. Pregnancy characteristics and women's future cardiovascular health: an underused opportunity to improve women's health? Epidemiologic Reviews 201436 57-70. (doi:10.1093/epirev/mxt006)

10 Dahabreh IJ, Trikalinos TA \& Paulus JK. Parity and risk of lung cancer in women: systematic review and meta-analysis of epidemiological studies. Lung Cancer 201276 150-158. (doi:10.1016/ j.lungcan.2011.10.014)

11 Al-Farsi YM, Brooks DR, Werler MM, Cabral HJ, Al-Shafei MA \& Wallenburg HC. Effect of high parity on the occurrence of 
prediabetes: a cohort study. Acta Obstetricia et Gynecologica Scandinavica 201089 1182-1186. (doi:10.3109/00016349. 2010.501854)

12 Kritz-Silverstein D, Barrett-Connor E \& Wingard DL. The effect of parity on the later development of non-insulin-dependent diabetes mellitus or impaired glucose tolerance. New England Journal of Medicine 1989321 1214-1219. (doi:10.1056/nejm198911023211802)

13 Tian Y, Shen L, Wu J, Chen W, Yuan J, Yang H, Wang Y, Liang Y \& $\mathrm{Wu}$ T. Parity and the risk of diabetes mellitus among Chinese women a cross-sectional evidence from the Tongji-Dongfeng cohort study. PLoS ONE 20149 e104810. (doi:10.1371/journal.pone.0104810)

14 Cure P, Hoffman HJ \& Cure-Cure C. Parity and diabetes risk among hispanic women from Colombia: cross-sectional evidence. Diabetology \& Metabolic Syndrome 2015 7 7. (doi:10.1186/s13098-015-0001-z)

15 Mueller NT, Mueller NJ, Odegaard AO, Gross MD, Koh WP, Yuan JM $\&$ Pereira MA. Higher parity is associated with an increased risk of type-II diabetes in Chinese women: the Singapore Chinese Health Study. BJOG 2013120 1483-1489. (doi:10.1111/1471-0528.12364)

16 Naver KV, Lundbye-Christensen S, Gorst-Rasmussen A, Nilas L, Secher NJ, Rasmussen S \& Ovesen P. Parity and risk of diabetes in a Danish nationwide birth cohort. Diabetic Medicine 201128 43-47. (doi:10.1111/j.1464-5491.2010.03169.x)

17 Fowler-Brown AG, de Boer IH, Catov JM, Carnethon MR, Kamineni A, Kuller LH, Siscovick DS \& Mukamal KJ. Parity and the association with diabetes in older women. Diabetes Care 201033 1778-1782. (doi:10.2337/dc10-0015)

18 Simmons D, Shaw J, McKenzie A, Eaton S, Cameron AJ \& Zimmet P. Is grand multiparity associated with an increased risk of dysglycaemia? Diabetologia 200649 1522-1527. (doi:10.1007/s00125-006-0276-6)

19 Manson JE, Rimm EB, Colditz GA, Stampfer MJ, Willett WC, Arky RA, Rosner B, Hennekens CH \& Speizer FE. Parity and incidence of non-insulin-dependent diabetes mellitus. American Journal of Medicine 199293 13-18. (doi:10.1016/0002-9343(92)90674-Z)

20 Stroup DF, Berlin JA, Morton SC, Olkin I, Williamson GD, Rennie D, Moher D, Becker BJ, Sipe TA \& Thacker SB. Meta-analysis of observational studies in epidemiology: a proposal for reporting. Meta-analysis of Observational Studies in Epidemiology (MOOSE) group. JAMA 2000283 2008-2012. (doi:10.1001/jama.283.15.2008)

21 Wells GA, Shea B, O'Connell D, Peterson J, Welch V, Losos M \& Tugwell P. The Newcastle-Ottawa Scale (NOS) for assessing the quality of nonrandomized studies in meta-analyses, 2009. (available at: http://www.ohri.ca/programs/clinical_epidemiology/ oxford.asp). Accessed on 31 March 2016.

22 Rostom A, Dubé C, Cranney A, Saloojee N, Sy R, Garritty C, Sampson M, Zhang L, Yazdi F, Mamaladze V et al. Evidence Reports/ Technology Assessments. Rockville, MD, USA: Agency for Healthcare Research and Quality (US); Appendix D. Quality Assessment Forms, 2004. (available at: http://www.ncbi.nlm.nih.gov/books/NBK35156/). Accessed on 31 March 2016.

23 Hamling J, Lee P, Weitkunat R \& Ambühl M. Facilitating metaanalyses by deriving relative effect and precision estimates for alternative comparisons from a set of estimates presented by exposure level or disease category. Statistics in Medicine 200827 954-970. (doi:10.1002/(ISSN)1097-0258)

24 Lau J, Ioannidis JP \& Schmid CH. Quantitative synthesis in systematic reviews. Annals of Internal Medicine 1997127 820-826. (doi:10.7326/0003-4819-127-9-199711010-00008)

25 Greenland S \& Longnecker MP. Methods for trend estimation from summarized dose-response data, with applications to meta-analysis. American Journal of Epidemiology 1992135 1301-1309.

26 Orsini N, Bellocco R \& Greenland S. Generalized least squares for trend estimation of summarized dose-response data. Stata Journal $2006640-57$.

27 Durrleman S \& Simon R. Flexible regression models with cubic splines. Statistics in Medicine 19898 551-561. (doi:10.1002/ (ISSN)1097-0258)
28 Harrell FE Jr, Lee KL \& Pollock BG. Regression models in clinical studies: determining relationships between predictors and response. Journal of the National Cancer Institute 198880 1198-1202. (doi:10.1093/jnci/80.15.1198)

29 Higgins JP, Thompson SG, Deeks JJ \& Altman DG. Measuring inconsistency in meta-analyses. BMJ 2003327 557-560. (doi:10.1136/ bmj.327.7414.557)

30 Egger M, Davey Smith G, Schneider M \& Minder C. Bias in meta-analysis detected by a simple, graphical test. BMJ 1997315 629-634. (doi:10.1136/bmj.315.7109.629)

31 Pyke DA. Parity and the incidence of diabetes. Lancet $1956 \mathbf{2 7 0}$ 818-820. (doi:10.1016/S0140-6736(56)91293-4)

32 Fitzgerald MG, Malins JM, O'Sullivan DJ \& Wall M. The effect of sex and parity on the incidence of diabetes mellitus. Quarterly Journal of Medicine 196130 57-70.

33 Middleton GD \& Caird FI. Parity and diabetes mellitus. British Journal of Preventive \& Social Medicine 196822 100-104. (doi:10.1136/ jech.22.2.100)

34 Boyko EJ, Alderman BW, Keane EM \& Baron AE. Effects of childbearing on glucose tolerance and NIDDM prevalence. Diabetes Care 199013 848-854. (doi:10.2337/diacare.13.8.848)

35 Kharazmi E, Lukanova A, Teucher B, Gross ML \& Kaaks R. Does pregnancy or pregnancy loss increase later maternal risk of diabetes? European Journal of Epidemiology 201227 357-366. (doi:10.1007/ s10654-012-9683-9)

36 Nicholson WK, Asao K, Brancati F, Coresh J, Pankow JS \& Powe NR. Parity and risk of type 2 diabetes: the Atherosclerosis Risk in Communities Study. Diabetes Care 200629 2349-2354. (doi:10.2337/ dc06-0825)

37 Charles MA, Pettitt DJ, McCance DR, Hanson RL, Bennett PH \& Knowler WC. Gravidity, obesity, and non-insulin-dependent diabetes among Pima Indian women. American Journal of Medicine 199497 250-255. (doi:10.1016/0002-9343(94)90008-6)

38 Alderman BW, Marshall JA, Boyko EJ, Markham KA, Baxter J \& Hamman RF. Reproductive history, glucose tolerance, and NIDDM in Hispanic and non- Hispanic white women: the San Luis Valley diabetes study. Diabetes Care 199316 1557-1564. (doi:10.2337/ diacare.16.12.1557)

39 Simons LA, Simons J, Friedlander Y \& McCallum J. Childbearing history and late-life mortality: the Dubbo study of Australian elderly. Age and Ageing 201241 523-528. (doi:10.1093/ageing/afs016)

40 Araneta MRG \& Barrett-Connor E. Grand multiparity is associated with type 2 diabetes in filipino american women, independent of visceral fat and adiponectin. Diabetes Care 201033 385-389. (doi:10.2337/dc09-1477)

41 Hanley AJ, McKeown-Eyssen G, Harris SB, Hegele RA, Wolever TM, Kwan J \& Zinman B. Association of parity with risk of type 2 diabetes and related metabolic disorders. Diabetes Care 200225 690-695. (doi:10.2337/diacare.25.4.690)

42 Collins VR, Dowse GK \& Zimmet PZ. Evidence against association between parity and NIDDM from five population groups. Diabetes Care 199114 975-981. (doi:10.2337/diacare.14.11.975)

43 Lao XQ, Thomas GN, Jiang CQ, Zhang WS, Yin P, Schooling M, Heys M, Leung GM, Adab P, Cheng KK et al. Parity and the metabolic syndrome in older Chinese women: the Guangzhou Biobank Cohort Study. Clinical Endocrinology 200665 460-469. (doi:10.1111/j.13652265.2006.02615.x)

44 Gunderson EP, Jacobs DR Jr, Chiang V, Lewis CE, Tsai A Quesenberry CP Jr \& Sidney S. Childbearing is associated with higher incidence of the metabolic syndrome among women of reproductive age controlling for measurements before pregnancy: the CARDIA study. American Journal of Obstetrics and Gynecology 2009201 177.e1-177.e9. (doi:10.1016/j.ajog.2009.03.031)

45 Hinkula M, Kauppila A, Nayha S \& Pukkala E. Cause-specific mortality of grand multiparous women in Finland. American Journal of Epidemiology 2006163 367-373. (doi:10.1093/aje/kwj048) 
46 Martinez G, Daniels K \& Chandra A. Fertility of men and women aged 15-44 years in the United States: National Survey of Family Growth, 2006-2010. National Health Statistics Reports 201251 $1-28$.

47 Solomon CG. The epidemiology of polycystic ovary syndrome: prevalence and associated disease risks. Endocrinology and Metabolism Clinics of North America 199928 247-263. (doi:10.1016/S08898529(05)70069-4)

48 Tobias DK, Gaskins AJ, Missmer SA, Hu FB, Manson JE, Buck Louis GM, Zhang C \& Chavarro JE. History of infertility and risk of type 2 diabetes mellitus: a prospective cohort study. Diabetologia 201558 707-715. (doi:10.1007/s00125-015-3493-z)

49 Dahlgren J. Pregnancy and insulin resistance. Metabolic Syndrome and Related Disorders 20064 149-152. (doi:10.1089/met.2006.4.149)

50 Barbour LA, McCurdy CE, Hernandez TL, Kirwan JP, Catalano PM \& Friedman JE. Cellular mechanisms for insulin resistance in normal pregnancy and gestational diabetes. Diabetes Care 200730 (Supplement 2) S112-S119. (doi:10.2337/dc07-s202)

51 Kuhl C. Etiology and pathogenesis of gestational diabetes. Diabetes Care 199821 (Supplement 2) B19-B26.

52 Cruz NG, Sousa LP, Sousa MO, Pietrani NT, Fernandes AP \& Gomes KB. The linkage between inflammation and Type 2 diabetes mellitus. Diabetes Research and Clinical Practice 201399 85-92. (doi:10.1016/j.diabres.2012.09.003)

53 Myatt L \& Cui X. Oxidative stress in the placenta. Histochemistry and Cell Biology 2004122 369-382. (doi:10.1007/s00418-004-0677-x)
54 Houstis N, Rosen ED \& Lander ES. Reactive oxygen species have a causal role in multiple forms of insulin resistance. Nature $2006 \mathbf{4 4 0}$ 944-948. (doi:10.1038/nature04634)

55 Pereira AC \& Martel F. Oxidative stress in pregnancy and fertility pathologies. Cell Biology and Toxicology 201430 301-312. (doi:10.1007/s10565-014-9285-2)

56 Bellamy L, Casas JP, Hingorani AD \& Williams D. Type 2 diabetes mellitus after gestational diabetes: a systematic review and meta-analysis. Lancet 2009373 1773-1779. (doi:10.1016/S01406736(09)60731-5)

57 Lykke JA, Langhoff-Roos J, Sibai BM, Funai EF, Triche EW \& Paidas MJ. Hypertensive pregnancy disorders and subsequent cardiovascular morbidity and type 2 diabetes mellitus in the mother. Hypertension 200953 944-951. (doi:10.1161/HYPERTENSIONAHA.109.130765)

58 Li S, Zhang M, Tian H, Liu Z, Yin X \& Xi B. Preterm birth and risk of type 1 and type 2 diabetes: systematic review and meta-analysis. Obesity Reviews 201415 804-811. (doi:10.1111/obr.2014.15.issue-10)

59 Mamun AA, Kinarivala M, O'Callaghan MJ, Williams GM, Najman JM \& Callaway LK. Associations of excess weight gain during pregnancy with long-term maternal overweight and obesity: evidence from $21 \mathrm{y}$ postpartum follow-up. American Journal of Clinical Nutrition 201091 1336-1341. (doi:10.3945/ajcn.2009.28950)

60 Al Mamun A, Mannan M, O'Callaghan MJ, Williams GM, Najman JM \& Callaway LK. Association between gestational weight gain and postpartum diabetes: evidence from a community based large cohort study. PLoS ONE 20138 e75679. (doi:10.1371/journal.pone.0075679)

Received 8 April 2016

Revised version received 11 June 2016

Accepted 21 June 2016 